\title{
SURFACE PROPERTIES OF NOVEL WOOD-BASED REINFORCED COMPOSITES MANUFACTURED FROM CRUSHED VENEERS AND PHENOLIC RESINS
}

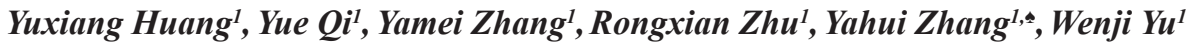

\begin{abstract}
This study was performed to determine the surface properties of novel wood-based reinforced composites made from poplar veneers and phenolic resins. The veneers with different thickness $(1,8 ; 4 ; 6 ; 8 \mathrm{~mm})$ were finely crushed and then were impregnated with phenolic resins to achieve different resin loading $(12,14,18 \%)$. Finally, they were laminated or random paved to manufacture novel wood-based reinforced composites with different target densities $\left(900-1100 \mathrm{~kg} / \mathrm{m}^{3}\right)$. With increased veneer thickness or resin content, the hardness of novel wood-based reinforced composites decreased and their roughness increased. The increase of density contributed to the increased hardness and decreased roughness. The surface wettability of novel wood-based reinforced composites appeared to be closely related to their surface roughness. There was a negative correlation between contact angle and roughness. The novel wood-based reinforced composites prepared by laminated mat formation showed higher hardness, lower roughness than those by random mat formation. Such data of surface properties can be applied to design the novel wood-based reinforced composites products with desired quality and provide basic information for further panel processing.
\end{abstract}

Keywords: Hardness, surface energy, surface roughness, surface wettability, wood composites.

\section{INTRODUCTION}

The scrimber manufacturing process has received considerable attention from researcher and industrialists in recent years. It is a kind of reconstituted wood product, which is manufactured from integrated parallel wood strips or veneers with addition of binders under application of temperature and pressure (He et al. 2016). Fast-growing species such as poplar (Li et al. 2016), Eucalyptus, bamboo (Chung and Wang 2017) and mulberry branches (Yu et al. 2015) are main raw materials for scrimber production. Compared with other wood composites such as particleboard and medium density fiberboard (MDF) (Candan et al. 2017), scrimber has excellent mechanical properties, which has the potential for structural applications in practical engineering.

The traditional scrimber manufacturing technique includes the whole log split into strands and this approach has a lot of drawbacks on account of the irregular shape of the wood units. Their uneven density and surface roughness lead to non-uniform adhesive and moisture distribution in the mats (Zhang et al. 2017). In our latest work, a process of veneers production, where the cut veneers were flattened and spit into strands by a pilot scale crushing machine, was implemented to manufacture novel wood-based reinforced composite (NWRCs) based on the traditional scrimber manufacturing process (Zhang et al. 2017). In the crushing machine, there are many special-shaped teeth on the round roller, so a series of dotted and/or linear shaped cracks formed in the veneers along the fiber direction. While maintaining high mechanical properties, the dimensional stability of this new product has been greatly improved. Surface properties of the substrate have significant effects on the quality of final products laminated with thin overlays. A large amount of research had been made to study the surface properties of untreated wood (Oberhofnerová et al. 2017), thermally compressed veneers (Aydin et al. 2005, Bekhata and Krystofiak 2016, Candan et al. 2010), overlaid particleboard and MDF (Büyüksarı 2013, Hiziroglu et al. 2004, Hiziroglu and Zarate 2007), wood polypropylene composites (Bledzki et al. 2010, Li 2014, Liu et al. 2016, Liu et al. 2010, Hutyrová et al. 2014). The techniques to evaluate the surface roughness and surface stability were also investigated in the literature. 
However, there has been no study carried out to characterize the surface properties of scrimber, not to mention this novel composite manufactured from crushed veneers. Most of the studies focus on the mechanical properties of scrimber because it is relatively new as compared to other wood-based products. Therefore, the objective of this study is to evaluate the surface properties of novel WRCs to provide an initial data to the panel industry. In addition, investigation was also carried out to study the effects of veneer thickness, resin content, mat formation and density on the surface properties of the final wood composite product.

\section{MATERIALS AND METHODS}

\section{Materials}

Poplar wood (Populus ssp.) with the age of 4-5 years was obtained from Hebei province (65\% of moisture content (MC), 30-35 of diameter and 380 420 kg/m $\mathrm{m}^{3}$ of density). The PF resin was purchased from Guangdong Dynea Chemical Industry Co (molecular weight of $904-1070,45 \%$-solid content, $45 \mathrm{cps}$ viscosity at $20^{\circ} \mathrm{C}$ obtained by rotating viscometer and $\mathrm{pH}$ of 9-10).

\section{Preparation of finely crushed poplar veneers}

After debarking, the round-wood with a length of $2 \mathrm{~m}$ was peeled into veneers with different thickness $(1,8$ $\mathrm{mm}, 4 \mathrm{~mm}, 6 \mathrm{~mm}$ and $8 \mathrm{~mm}$ ). Afterwards, the veneers were cut into strips with a width of $200 \mathrm{~mm}$, then the veneers entered the crushing machine (Figure 1) to obtain the fluffed poplar veneers with a series of uniform linear-shaped cracks along the grain direction. The crushed veneers were dried in a kiln to approximately $10 \%$ of MC.
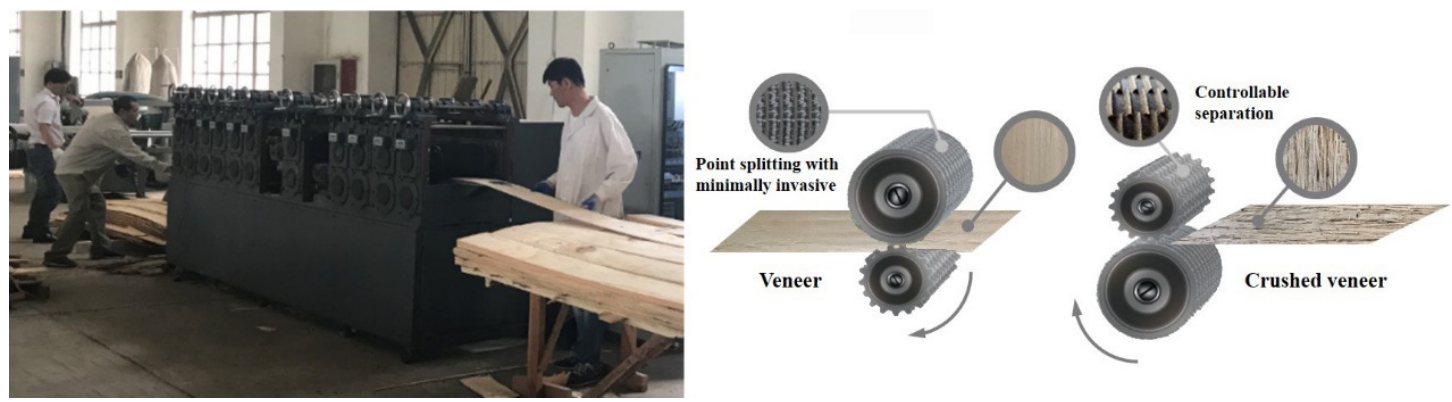

Figure 1: The photo of the crushing machine and its working principle.

\section{Preparation of NWRCs}

The crushed veneers were saturated in PF resin to achieve desired resin content $(10 \%, 14 \%$ and $18 \%)$ and dried again to $12 \% \mathrm{MC}$. Cold-pressing and hot-curing were used in the forming process. The crushed veneers were weighed according to the desired density $\left(900-1100 \mathrm{~kg} / \mathrm{m}^{3}\right)$ and then laminated or paved randomly along the grain direction in the mold. After being pressed in a cold pressing machine at room temperature, the veneers were placed in the air-circulated baking chamber at $120 \sim 130^{\circ} \mathrm{C}$ for $12 \mathrm{~h}$ to achieve the curing of PF resin. The obtained NWRCs with dimensions of $2000 \mathrm{~mm}$ (length) $\times 200 \mathrm{~mm}$ (width) $\times 150 \mathrm{~mm}$ (thickness) were conditioned in a chamber at $65 \% \pm 5 \%$ relative humidity $(\mathrm{RH})$ at $20 \pm 2^{\circ} \mathrm{C}$ for 2 weeks before testing. Eight pieces of NWRC were manufactured under each condition, and five samples were cut from each NWRC. The conditions used for manufacturing NWRCs are listed in Table 1 in detail. 
Table 1: Conditions used for manufacturing NWRCs.

\begin{tabular}{|c|c|c|c|}
\hline Veneer thickness $\mathbf{( m m )}$ & $\begin{array}{c}\text { Density } \\
\left(\mathbf{k g} / \mathbf{m}^{\mathbf{3}} \mathbf{)}\right.\end{array}$ & Mat formation & $\begin{array}{c}\text { Resin content } \\
\mathbf{( \% )}\end{array}$ \\
\hline 1,8 & 900 & laminated & 14 \\
\hline 4,0 & 900 & laminated & 14 \\
\hline 6,0 & 900 & laminated & 14 \\
\hline 6,0 & 900 & laminated & 14 \\
\hline 6,0 & 800 & laminated & 14 \\
\hline 6,0 & 1000 & laminated & 14 \\
\hline 6,0 & 1100 & laminated & 14 \\
\hline 6,0 & 900 & laminated & 10 \\
\hline 6,0 & 900 & laminated & 18 \\
\hline 6,0 & 900 & random & 14 \\
\hline
\end{tabular}

\section{Measurement of hardness}

The surface hardness of the NWRC samples $(70 \times 50 \times 20 \mathrm{~mm})$ was determined by XHR-150 plastic Rockwell hardness tester according to GB/T1941-2009. The hemispherical steel indenter with radius of 5,64 mm was used in the test. The indenter was pressed into the test surface until the depth was $5,64 \mathrm{~mm}$. For the specimens which were easy to deform in the pressurization process, the depth of the head was allowed to be reduced to $2,82 \mathrm{~mm}$.

\section{Determination of surface roughness}

The surface roughness of the NWRC samples was measured with a TIME 3230 surface roughometer. Specimens of $80 \times 20 \mathrm{~mm}$ squares were cut and then sanded with 240 -grit sand paper for $1 \mathrm{~min}$. A Gaussian filter with a cutoff wavelength of $0,8 \mathrm{~mm}$ was used to transform the data. Two roughness parameters, average roughness $\left(R_{\mathrm{a}}\right)$, mean peak-to-valley height $\left(R_{\mathrm{z}}\right)$, were used to evaluate surface roughness of the samples. Three specimens were sampled for each group with the same density, and four random measurements of surface roughness were taken per specimen.

\section{Surface morphology of NWRCs}

The surface morphology of NWRCs were observed with an optical microscope (VHX-1000E), a new ultra-depth 3-dimensional microscopy system (UDM), made by KEYENCE.

\section{Measurement of contact angle and calculation of extension and penetration rate parameter}

Three liquids (distilled water, formamide, and diiodomethane), which may be used in coating adhesion during the process of surface finishing, were chosen to determine the wettability of NWRCs. The NWRC samples were cut into small blocks with a size of $80 \times 42 \times 6 \mathrm{~mm}$, and then, their lateral surfaces were sanded with 240 -grit sand paper. The wetting behavior was determined on the tangential section of the samples by the sessile drop method with an OCA20 contact angle measuring instrument (Dataphysics, Germany). Five tests were performed on each specimen, and two replicates were carried out for each group. An automatic micro syringe was used to dispense drops of approximately $4 \mu \mathrm{L}$ test liquid. The contact angle of droplet on each sample was measured at intervals of $1 \mathrm{~s}$ after the liquid droplet fell down on the sample surface.

In the process of liquid wetting, the contact angle gradually decreases with the time attributable to the extension and penetration of the liquid, and finally trends to relative balance. For an ideal solid-liquid system, the speed of extension and penetration depends on the contact angle at a given time (Shi and Gardner 2001):

$$
\frac{d \theta}{d t}=-K \theta
$$


where is the constant of the change of contact angle.

With the prolongation of time, the extension and penetration rate of the contact angle is slowed down, and the change speed of the contact angle decreases, and finally is close to zero. Thus, a limit is added to Equation 1.

$$
\frac{d \theta}{d t}=-K \theta\left(1-\frac{\theta_{i}-\theta}{\theta_{i}-\theta_{e}}\right)
$$

Where is the initial contact angle and is the equilibrium contact angle. In the Equation 2, $K$ represents the rate constant of the reduction of relative contact angle. Change the form of the Equation 2.

$$
\frac{d \theta}{d t}=K \theta\left(\frac{\theta_{e}-\theta}{\theta_{i}-\theta_{e}}\right)
$$

After rearranging Equation 3, the Equation 4 is obtained.

$$
\theta=\frac{\theta_{i} \theta_{e}}{\theta_{i}+\left(\theta_{e}-\theta_{i}\right)} \exp \left[K\left(\frac{\theta_{e}}{\theta_{e}-\theta_{i}}\right) t\right]
$$

The change of contact angle is caused by the extension and penetration of the liquid on the surface of the solid. Therefore, the $K$ value can also be considered as the diffusion rate parameter of the liquid on the surface of the solid, which is used to characterize the extension and penetration rate of a liquid on a solid surface. The higher the $K$ value, the more rapidly the contact angle reaches equilibrium and the faster the liquid penetrates and spreads, and vice versa. The $K$ value of a particular liquid-solid system can be determined by curve-fitting the experimental data to Equation 4 using a nonlinear method (Huang et al. 2012).

\section{Calculation of surface free energy}

The surface free energy of samples with various densities was also calculated by the Lifshitze-van der Waals/acid-base (LW-AB) approach (Oss 1993, Gindl et al. 2001, Wålinder 2002, Santos and Goncalvez 2016). According to this approach, the surface free energy is a sum of Lifshitz-van der Waals component $\left(\gamma^{\mathrm{LW}}\right)$ and the acid-base $\left(\gamma^{\mathrm{AB}}\right)$ component. The mathematical approach for the solid/liquid interfacial tension is given by Equation 5:

$$
\gamma_{L}(1+\cos \theta)=2\left(\sqrt{\gamma_{S}^{L W} \gamma_{L}^{L W}}+\sqrt{\gamma_{S}^{+} \gamma_{L}^{-}}+\sqrt{\gamma_{S}^{-} \gamma_{L}^{+}}\right)
$$

where is the contact angle, and the subscripts and denote solid and liquid phases, respectively. denotes electron-accepting component, and is electron-donating component. 


\section{RESULTS AND DISCUSSION}

\section{Hardness of NWRCs}

Hardness reflects the resistance of a material against indentation. Figure $2 \mathrm{a}$ shows the effect of veneer thickness on the hardness of NWRCs. In the case of density of $900 \mathrm{~kg} / \mathrm{m}^{3}$ as well as resin content of $14 \%$, the hardness of NWRCs gradually decreased with the increase in the thickness of veneers. The maximum decline $(11,4 \%)$ appeared when the veneer thickness increased from $6 \mathrm{~mm}$ to $8 \mathrm{~mm}$. The thicker the veneer, the more severe the cell wall collapsed during the fluffing process. Thus, the hardness of the product decreased when the veneers were manufactured into NWRCs.
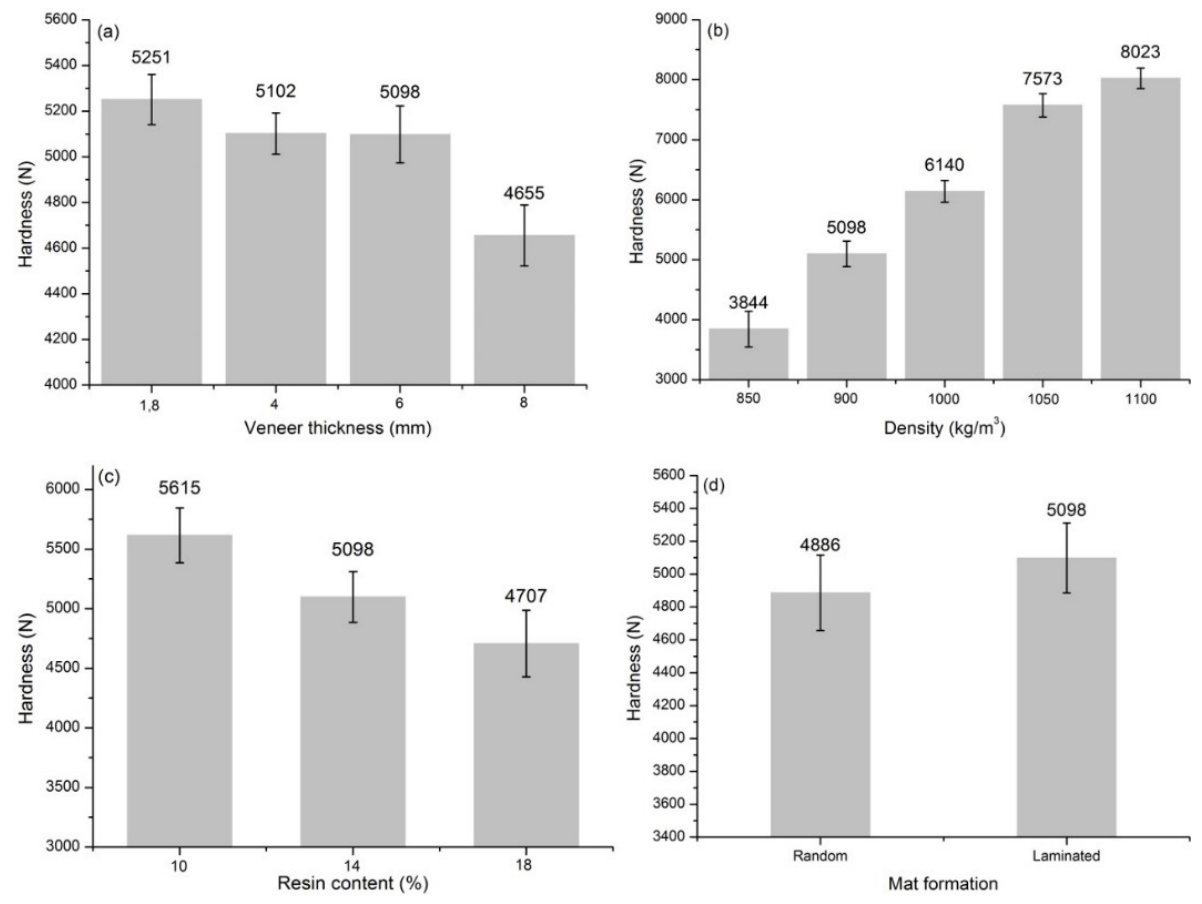

Figure 2: The influence of veneer thickness (a), density (b), resin content (c) and mat formation (d) on the hardness of NWRCs

In the case of 6-mm-thick veneers as well as resin content of $14 \%$, the hardness of NWRCs increased as density increased (Figure 2b). This was attributable to the higher densification on the face layers of samples resulting in harder surface. Similar results were observed by several researchers (Fang et al. 2012, Unsal and Candan 2008). Fang et al. (2012) found that Brinell hardness of densified veneers was approximately two or three times that of control for both aspen and hybrid poplar. Unsal and Candan (2008) stated that the increase of hardness of solid pine wood with increasing press pressure and temperature could be attributed to the increase in density of the specimens. As the density increased from $850 \mathrm{~kg} / \mathrm{cm}^{3} \mathrm{~g} \mathrm{~cm}^{-3}$ to $1050 \mathrm{~kg} / \mathrm{cm}^{3}$, the hardness of the NWRCs nearly doubled. While the density exceeded $1050 \mathrm{~kg} / \mathrm{cm}^{3}$, the increase in hardness of the NWRCs was not obvious. The NWRCs with density of $1100 \mathrm{~kg} / \mathrm{cm}^{3}$ had the greatest hardness with value of $8023 \mathrm{~N}$.

Under the process conditions of 6-mm-thick veneers and density of $900 \mathrm{~kg} / \mathrm{cm}^{3}$, the hardness of NWRCs prepared by laminated mat formation gradually decreased with an increase in resin content (Figure 2c). Compared with the NWRCs with resin content of $10 \%$, those with resin content of $18 \%$ had a $16,2 \%$ decrease in hardness. However, only a slight decrease of $4,2 \%$ was found from the hardness of NWRCs prepared by parallel mat formation to that by random mat formation (Figure 2d), indicating that mat formation seemed to have no significant effect on the hardness of NWRCs. In the scope of the design of this study, the hardness of NWRCs fell in the region of 4000-9000 N. The lowest hardness was equivalent to that of cherry, walnut and elm, while the highest hardness was comparable to sandalwood (Santalum album). 


\section{Roughness of NWRCs}

Figure 3a shows average values of roughness parameters obtained from the surfaces of NWRCs at different veneer thickness levels. The smoothest surface was observed in NWRCs of $2 \mathrm{~mm}$-thick veneers $\left(R_{\mathrm{a}}=2,68 \mu \mathrm{m}\right)$. The original surface quality of NWRCs were better than that of Pterocarya fraxinifolia LVL from 2,3-mmthick rotary peeled veneers $\left(R_{\mathrm{a}}=6,83 \mu \mathrm{m}\right)$ (Gungor et al. 2006) and that of Sorbus aucuparia L. LVL from 1,6-mm-thick veneers $\left(R_{\mathrm{a}}=5,13 \mu \mathrm{m}\right)\left(\mathrm{Kol}\right.$ et al. 2009). The $R_{\mathrm{a}}$ value of the NWRCs decreased with increasing veneer thickness. As for LVL and plywood, the veneer thickness only had significant effects on the mechanical properties and dimensional stability of the panels (Melo 2014), while seemingly it had no effects on the surface quality. However, during the manufacturing process of NWRCs, the surface quality of the veneers was changed after fluffing. There were more cracks on the surface of the thick veneers which bore more pressure during the crushing process, thereby affecting the surface quality of the final products.

As density increased from $800 \mathrm{~kg} / \mathrm{cm}^{3}$ to $1050 \mathrm{~kg} / \mathrm{cm}^{3}$, the $R_{\mathrm{a}}$ value of NWRCs gradually decreased (Figure $3 \mathrm{~b}$ ). The increased density resulted in the enhancement of dense effect of the NWRCs, thereby leading to a more compact surface. Similar result was found by Akbulut and Koç (2004) in the study of MDF, of which increasing the panel density decreased the roughness of the profiled areas.

On the contrary, there was a positive correlation between the resin content and the surface roughness, where the $R_{\mathrm{a}}$ value of NWRCs increased with increasing the resin content (Figure 3c). The increase in the resin content contributed to a decrease in the wood content of the composite, which contributed to the increased surface roughness. The $R_{\mathrm{a}}$ values of NWRCs manufactured by random mat formation are higher than those of the samples by parallel mat formation (Figure 3d). This rougher surface could be ascribed to the tiny cavity formed by the folding and stacking of the material during the pressing process.
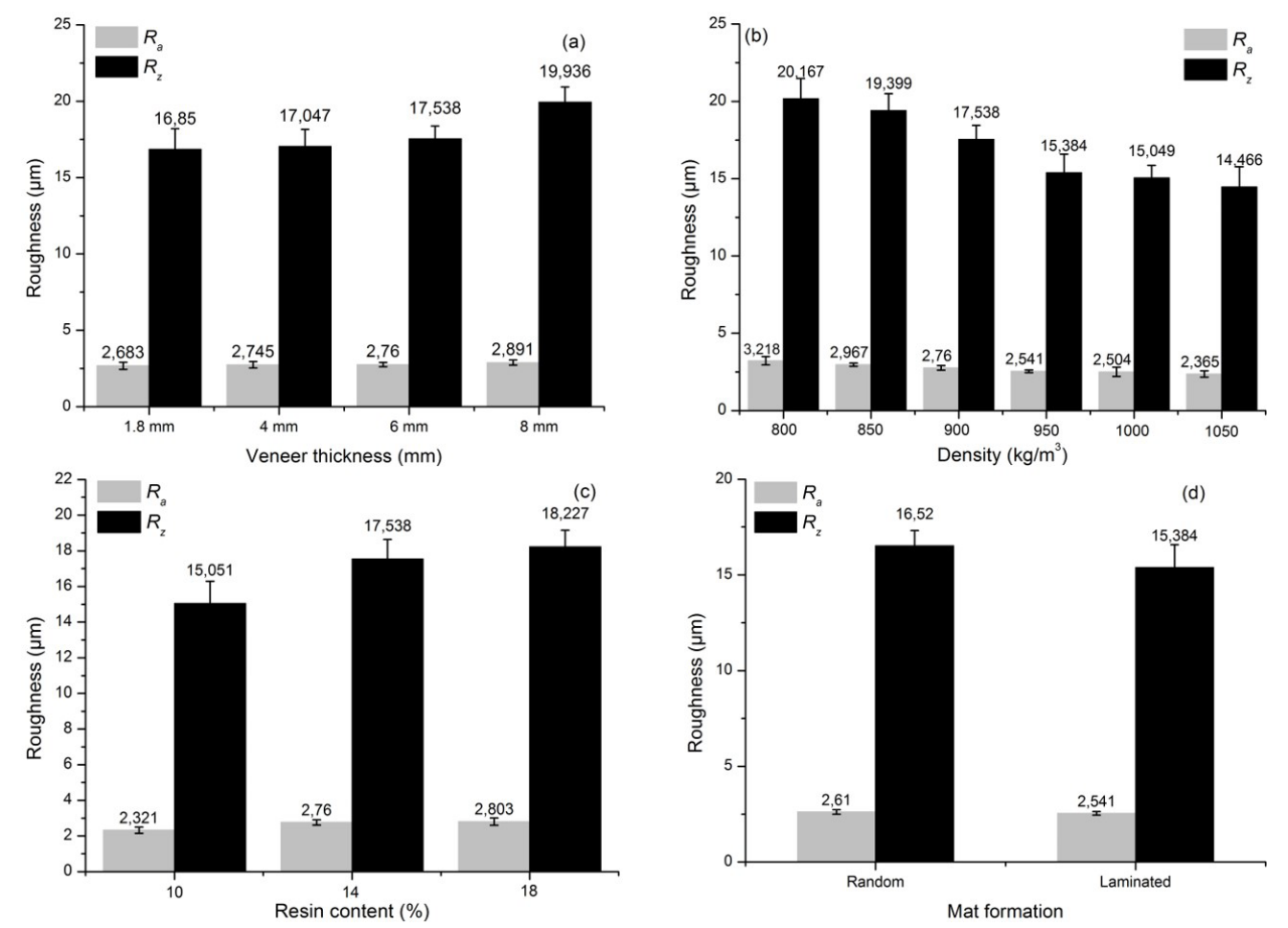

Figure 3: The influence of veneer thickness (a), density (b), resin content (c) and mat formation (d) on the surface roughness of NWRCs.

The $R_{\mathrm{z}}$ parameter of NWRCs had similar trends to the $R_{\mathrm{a}}$ values. The $R_{\mathrm{z}}$ value of NWRCs also increased with increasing the veneer thickness. The increase $(13,7 \%)$ was found to be significant when the thickness exceeded $6 \mathrm{~mm}$. Decreasing the density or increasing the resin content also resulted in the increase of the $R_{\mathrm{z}}$ value. 
Under the observation of the ultra-depth microscope, the surface appearance and the line roughness are consistent with the above surface roughness results (Figure 4a, Figure 4b, Figure 4c, Figure 4d). In addition, in the case of different resin content, high resin content can form a more uniform package for the material (Figure $4 \mathrm{e})$.
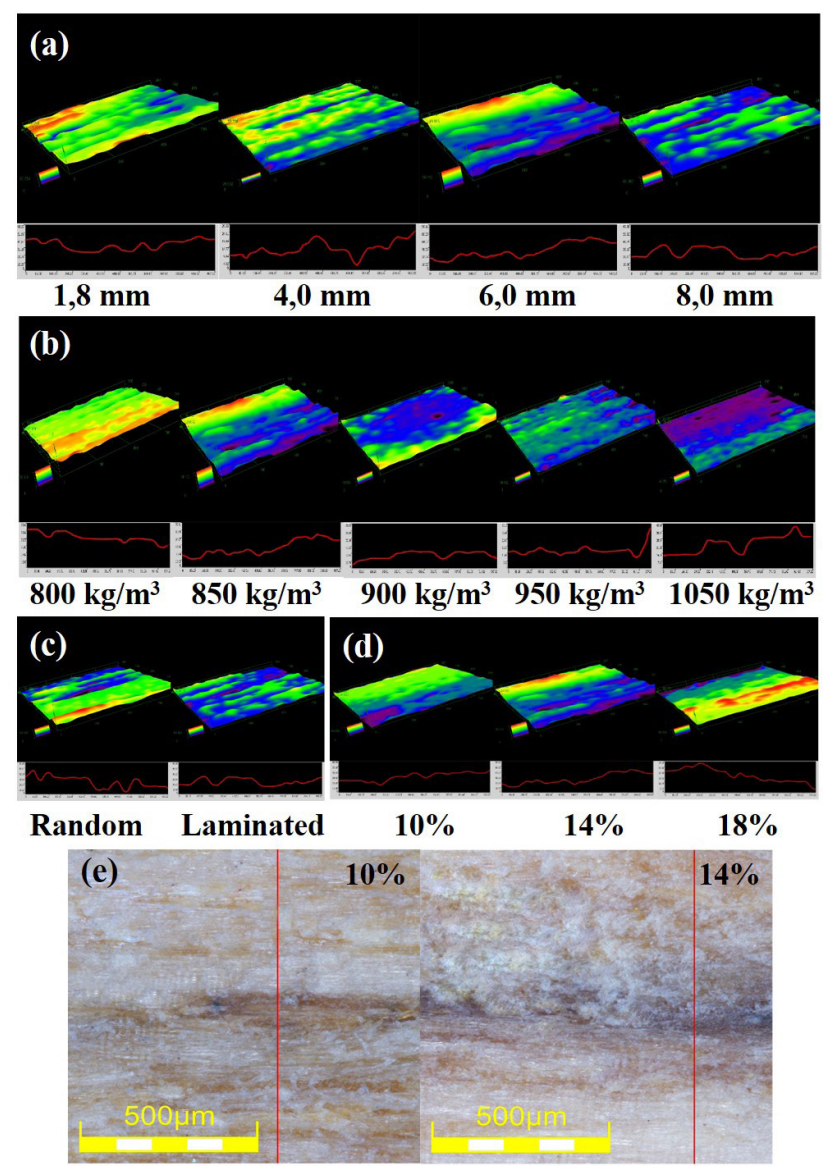

Figure 4: The influence of veneer thickness (a), density (b), mat formation (c) and resin content (d) on the surface morphology and line roughness of NWRCs and surface packages of NWRCs with different resin content (e).

\section{Surface wettability of NWRCs}

The initial stage of liquid droplets formed on the surface of the NWRCs could be considered as stable. After a short period of the thermodynamic stability, the droplets are affected by the surrounding natural environment. In the macroscopic view, the contact angle changed with time (Figure 5). With the increase in the thickness of the veneers, the initial contact angles of NWRCs gradually decreased, and the $K$ values increased with rising the thickness of the veneers. 

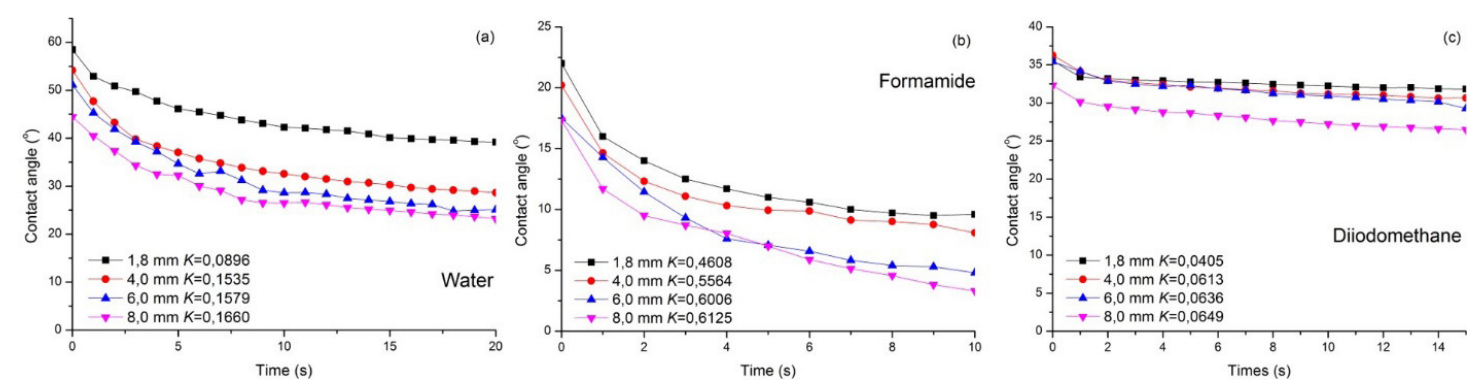

Figure 5: Dynamic contact angles by three different liquids as a function of a time for the NWRCs with different veneer thickness.

The distilled water showed the largest initial contact angle on the surface of the material, while formamide showed the smallest one. On the contrary, the $K$ value for formamide was the highest, followed by the distilled water, the last was diiodomethane. Similar results were found by several researchers (Huang et al. 2012, Stehr et al. 2001). Huang et al (2012)found that formamide has the highest $K$ values comparted with those of water and ethylene glycol. Stehr et al. (2001) stated that formamide is a strong hydrogen-bonding liquid that radically decreases the interfacial free energy at the liquid-solid interface through acid base interactions, thereby increasing the spreading and penetration rate. The change of surface contact angle is mainly caused by the acid-base $\left(\gamma^{\mathrm{AB}}\right)$ component of wetting liquid. Further, it is affected by the electron-donating component of the liquid $\left(\gamma_{L}^{-}\right)$. The greater the $\gamma_{L}^{-}$value, the greater the change of contact angle, and the better the permeability. The influence of the veneer thickness on the contact angle of WRCs was mainly caused by the roughness, and the roughness of the surface geometry was the main factor to determine the surface wettability. According to the Wenzel theoretical model, for a given surface, the roughness factor of the surface has amplification effect on the surface wettability. Increasing the roughness would make the hydrophilic surface more hydrophilic, and the hydrophobic surface more hydrophobic. Therefore, the results of this study were also fully consistent with the Wenzel theory model. The increase of the veneer thickness led to the increase of the roughness, which improved the surface wettability of the material and reduced the contact angle.

Figure 6 shows the dynamic contact angles by three different liquids as a function of a time for the NWRCs with different densities. The initial contact angle of NWRC was positively related to its density. The distilled water still showed the largest initial contact angle on the material surface, while formamide showed the smallest. The increase of contact angle could be attributed to the decrease of the surface roughness with rising the density.
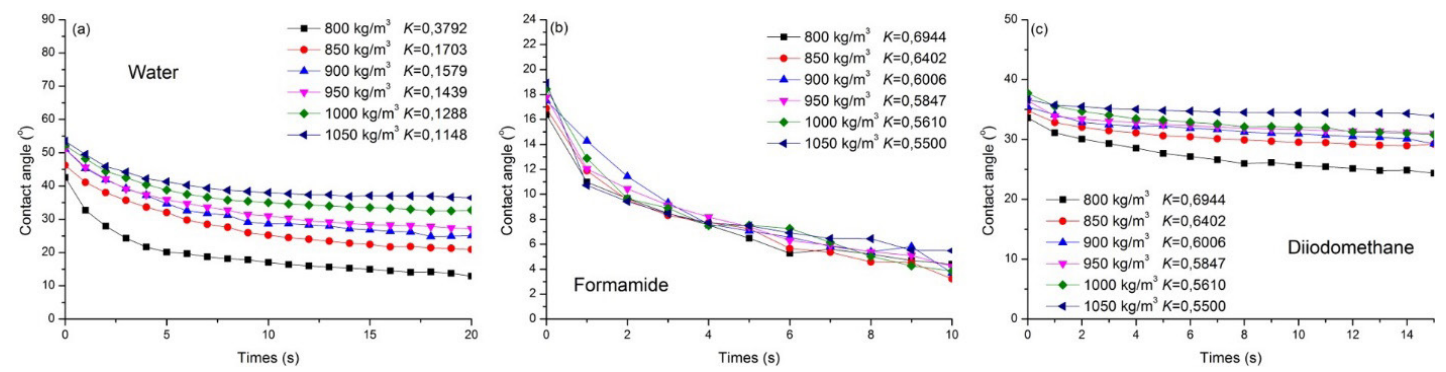

Figure 6: Dynamic contact angles by three different liquids as a function of a time for the NWRCs with different densities.

The change of contact angle with resin content or mat formation was closely related to the change of the roughness (Figure 7). The increase of the resin content resulted in the increase of surface roughness, thus reducing the contact angle. The NWRCs manufactured by random mat formation has rougher surface, correspondingly their contact angles are higher than the samples by parallel mat formation. 

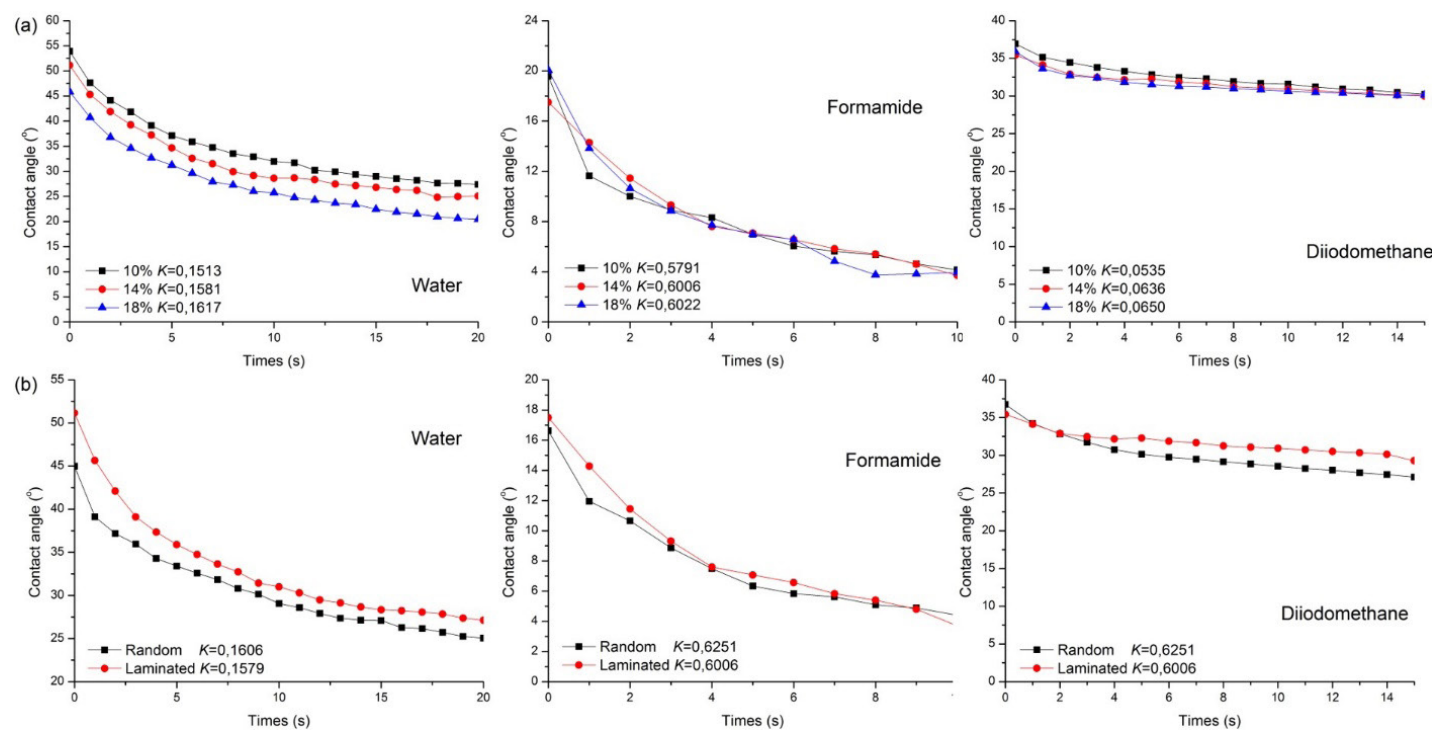

Figure 7: Dynamic contact angles by three different liquids as a function of a time for NWRCs with different resin content (a) and mat formation (b).

\section{Surface free energy}

As seen from Table 2, the surface free energv of the material $\left(\gamma_{S}^{T}\right)$ was composed of Lifshitz van der Waals force $\left(\gamma_{S}^{L W}\right)$ and acid base force $\left(\gamma^{\mathrm{AB}}\right)$, where $\gamma_{S}^{L W}$ occupied the main part. The size of the acid energy factor $(\gamma+)$ and the basic energy factor $(\gamma-)$ indicated the electronic granting ability and proton granting ability, respectively. With the increase of the veneer thickness, the surface free energy of NWRCs gradually increased attributahle to the increase of $\gamma_{S}^{L W}$. As the density increases, the surface free energy of NWRCs also increased, whereas $\gamma_{S}^{L W}$ gradually decreased. On the contrary, $\gamma^{\mathrm{AB}}$ increased, suggesting the increase of the surface polarity. With the increase of resin content, the surface free energy of NWRCs decreased slightly. The difference of the surface free energy was caused by $\gamma^{\mathrm{AB}}$.

The increase of resin content made the material to be evenly wrapped, resulting in a blunt surface. This reduced the surface polarity, which led to a decrease in the acid-base properties of the surface. The surface free energy of NWRCs prepared by random mat formation was slightly higher than that by parallel mat formation.

Table 2: Surface tension components of NWRCs from acid-base model.

\begin{tabular}{|c|c|c|c|c|c|c|c|c|c|c|c|c|c|c|c|}
\hline \multirow{2}{*}{ Parameters } & \multicolumn{4}{|c|}{ Veneer thickness $(\mathrm{mm})$} & \multicolumn{6}{|c|}{ Density $\left(\mathrm{g} \mathrm{cm}^{-3}\right)$} & \multicolumn{3}{|c|}{ Resin content } & \multicolumn{2}{|c|}{ Mat formation } \\
\hline & 1,8 & 4 & 6 & 8 & 0,8 & 0,85 & 0,9 & 0,95 & 1 & 1,05 & $10 \%$ & $14 \%$ & $18 \%$ & Laminated & Random \\
\hline$\gamma_{S}^{T}\left(\mathrm{~mJ} / \mathrm{m}^{2}\right)$ & 57,17 & 57,41 & 57,7 & 57,63 & 56,77 & 57,34 & 57,7 & 57,77 & 57,86 & 57,81 & 57,84 & 57,70 & 57,53 & 57,70 & 57,80 \\
\hline$\gamma_{s}^{L W}\left(\mathrm{~mJ} / \mathrm{m}^{2}\right)$ & 43,25 & 43,68 & 43,72 & 45,29 & 46,29 & 44,72 & 43,72 & 43,49 & 43,38 & 42,27 & 43,58 & 43,72 & 43,94 & 43,72 & 44,79 \\
\hline$\gamma^{A B}\left(\mathrm{~mJ} / \mathrm{m}^{2}\right)$ & 13,93 & 13,73 & 13,98 & 12,35 & 10,48 & 12,91 & 13,98 & 14,28 & 14,48 & 15,54 & 14,26 & 13,98 & 13,59 & 13,98 & 13,00 \\
\hline$\gamma^{+}\left(\mathrm{mJ} / \mathrm{m}^{2}\right)$ & 1,76 & 1,24 & 1,19 & 0,89 & 0,54 & 0,91 & 1,19 & 1,29 & 1,41 & 1,97 & 1,31 & 1,19 & 1,03 & 1,19 & 1,03 \\
\hline$\gamma^{-}\left(\mathrm{mJ} / \mathrm{m}^{2}\right)$ & 27,5 & 37,93 & 41,23 & 43,06 & 50,60 & 45,80 & 41,23 & 39,56 & 37,30 & 30,6 & 38,73 & 41,23 & 44,60 & 41,23 & 41,12 \\
\hline
\end{tabular}




\section{CONCLUSIONS}

This study evaluated surface properties including hardness, roughness, wettability and surface energy of novel wood-based reinforced composites (NWRCs) from crushed poplar veneers under different technical conditions. Our finding suggested that increasing the density and decreasing the veneer thickness or resin content could improve the hardness of NWRCs and reduce their surface roughness. The surface wettability of NWRCs was closely related to their surface roughness. Such data can be applied for practical use in manufacturing NWRCs with controlled quality.

\section{ACKONWLEDGMENTS}

The authors gratefully acknowledge the financial support from the National Key Research and Development Program of China "Integration and demonstration of production technology of green and environmentally friendly wood materials" (2017YFD0601205)

\section{REFERENCES}

Akbulut, T.; Koc, E. 2004. Effects of panel density, panel temperature, and cutter sharpness during edge machining on the roughness of the surface and profiled areas of medium density fiberboard. Forest Products Journal 54(12): 67-70.

Aydin, I.; Colakoglu, G.; Hiziroglu, S. 2005. Surface characteristics of spruce veneers and shear strength of plywood as a function of log temperature in peeling process. International Journal of Solids and Structures 43(20): 6140-6147.

Bekhata P.; Krystofiak, T. 2016. The influence of short-term thermo-mechanical densification on the surface wettability of wood veneers. Maderas-Cienc Tecnol 18(1): 79-90.

Bledzki, A.K.; Mamun, A.A.; Volk, J. 2010. Physical, chemical and surface properties of wheat husk, rye husk and soft wood and their polypropylene composites. Composites: Part A 41(4): 480-488.

Büyüksarı, Ü. 2013. Surface characteristics and hardness of MDF panels laminated with thermally compressed veneer. Composites: Part B 44(1): 675-678.

Candan, Z.; Shaler, M.S.; Heller, J.J.P.; Edgar, R. 2017. Enhancing dimensional stability of oriented strand composites within biorefinery. Maderas-Cienc Tecnol 19(3): 387-398.

Candan, Z.; Hiziroglu, S.; McDonald, A.G. 2010. Surface quality of thermally compressed Douglas fir veneer. Materials and Design 31(7): 3574-3577.

Chung, M.J.; Wang, S.Y. 2017. Mechanical properties of oriented bamboo scrimber boards made of Phyllostachys pubescens (moso bamboo) from Taiwan and China as a function of density. Holzforschung 72(2): 151-158.

Fang, C.; Mariotti, N.; Cloutier, A.; Koubaa, A.; Blanchet, P. 2012. Densification of wood veneers by compression combined with heat and steam. European Journal of Wood \& Wood Products 70(1-3): 155-163.

Gindl, M.; Sinn, G.; Gindl, W.; Reiterer, A.; Tschegg, S. 2001. A comparison of different methods to calculate the surface free energy of wood using contact angle measurements. Colloids \& Surfaces A Physicochemical \& Engineering Aspects 181(1-3): 279-287.

Gungor, N.; Ayrilmis, N.; Kantay, R. 2006. Selected physical and mechanical properties of LVL made from Pterocarya fraxinifolia (Lam.) Spach. Forest Products Journal 56(5): 82-85. 
He, M.J.; Zhang, J.; Li, Z.; Li, M.L. 2016. Production and mechanical performance of scrimber composite manufactured from poplar wood for structural applications. Journal of Wood Science 62(5): 429-440.

Hutyrová, Z.; Harničarová, M.; Zajac, J.; Valíček, J.; Mihok, J. 2014. Experimental study of surface roughness of wood plastic composites after turning. Advanced Materials Research 856: 108-112.

Hiziroglu, S.; Jarusombuti, S.; Fueangvivat, V. 2004. Surface characteristics of wood composites manufactured in Thailand. Building and Environment 39(11): 1359-1364.

Hiziroglu, S.; Zarate, S. 2007. Mechanical properties and surface characteristics of colombian wood composites. Journal of Composite Materials 41(18): 2225-2234.

Huang, X.; Kocaefe, D.; Boluk, Y.; Kocaefe, Y.; Pichette, A. 2012. Effect of surface preparation on the wettability of heat-treated jack pine wood surface by different liquids. European Journal of Wood \& Wood Products 70(5): 711-717.

Kol, H.S.; Keskin, H.; Korkut, S.; Akbulut, T. 2009. Laminated veneer lumber from Rowan (Sorbus aucuparia Lipsky). African Journal of Agricultural Research 4(10): 1101-1105.

Li, Y. 2014. Effect of woody biomass surface free energy on the mechanical properties and interface of wood/polypropylene composites. Journal of Adhesion Science and Technology 28(2): 215-224.

Li, Z.; He, M.; Tao, D.; Li, M. 2016. Experimental buckling performance of scrimber composite columns under axial compression. Composites Part B: Engineering 86: 203-213.

Liu, R.; Sun, W.; Cao, J.; Wang, J. 2016. Surface properties of in situ organo-montmorillonite modified wood flour and the influence on mechanical properties of composites with polypropylene. Applied Surface Science 361: 234-241.

Liu, Y.; Tao, Y.; Lv, X.; Zhang, Y.; Di, M. 2010. Study on the surface properties of wood/polyethylene composites treated under plasma. Applied Surface Science 257: 1112-1118.

Melo, P. 2014. Influence of veneer thickness on the properties of LVL from Paricá (Schizolobium amazonicum) plantation trees. European Journal of Wood \& Wood Products 72(2): 191-198.

Oberhofnerová, E.; Pánek, M.; Garcíacimarras, A. 2017. The effect of natural weathering on untreated wood surface. Maderas-Cienc Tecnol 19(2): 173-184.

Oss, C.J. 1993. Acid-base interfacial interactions in aqueous media. Colloids and Surfaces A: Physicochemical and Engineering Aspects 78: 1-49.

Shi, S.Q.; Gardner, D.J. 2001. Dynamic adhesive wettability of wood. Wood \& Fiber Science 33: 58-68.

Santos, S.N.C.; Gonçalves, D. 2016. Variations in wettability on heat-treated wood surfaces: contact angles and surface free energy. Maderas-Cienc Tecnol 18(2): 383-394.

Stehr, M.; Gardner, D.J.; Wålinder, M.E.P. 2001. Dynamic wettability of different machined wood surfaces. The Journal of Adhesion 76(3): 185-200.

Unsal, O.; Candan, Z. 2008. Moisture content, vertical density profile and janka hardness of thermally compressed pine wood panels as a function of press pressure and temperature. Drying Technology 26(9): 11651169.

Wålinder, M.E.P. 2002. Study of Lewis acid-base properties of wood by contact angle analysis. Holzforschung 56(4): 363-371.

Yu, H.; Fang, C.; Xu, M.; Guo, F.; Yu, W. 2015. Effects of density and resin content on the physical and mechanical properties of scrimber manufactured from mulberry branches. Journal of Wood Science 61(2): $159-164$ 
Zhang, Y.; Huang, X.; Zhang, Y.; Yu, Y.; Yu, W. 2017. Scrimber board (SB) manufacturing by a new method and characterization of SB's mechanical properties and dimensional stability. Holzforschung 72(4): 283-289. 